\title{
Formulation and Evaluation of Oral Fast Dissolving Films of Poorly Soluble Drug Ezetimibe Using Transcutol Hp
}

\author{
Pondugula Sudhakara Reddy ${ }^{1}, \mathrm{KV}$ Ramana Murthy² ${ }^{\star}$ \\ ${ }^{1}$ Star "A" apartments, Bhagyanagar colony, Kukatpally, Hyderabad, Telangana 500072, INDIA. \\ 2Professor of Pharmaceutics, A.U. College of Pharmaceutical Sciences, Andhra University, Visakhapatnam - 530003 , Andhra Pradesh, \\ INDIA.
}

\begin{abstract}
Introduction: The objective of the present formulation research is to deliver the drugs at a faster rate and to provide immediate onset of action in a shorter period of time with improved bioavailability. Materials and Methods: Ezetimibe, a gift sample from Lupin Ltd., Pune, Transcutol HP, a gift sample from Gattefosse India Pvt. Ltd., Goa., HPMC E5, HPMC E6, HPMC E15 are gift samples from Colorcon India Pvt. Ltd. Results and Discussion: Among prepared formulations coded E1 to E20, formulation E6 was shown promising results, hence further studies done without transcutol HP and documented clear results saying that, without transcutol HP has shown around $50 \%$ of drug even after 90 min of time, whereas within 10 min complete drug release observed with transcutol HP formulation. Conclusion: The study clearly indicated the influence of transcutol HP in enhancing the solubility of the poorly soluble drugs as the films made without transcutol HP failed to give the desired release characteristics within $10 \mathrm{~min}$.
\end{abstract}

Key words: Ezetimibe, Transcutol HP, HPMC E5, HPMC E6, HPMC E15, Pectin.

\section{INTRODUCTION}

The objective of the present formulation research is to deliver the drugs at a faster rate and to provide immediate onset of action in a shorter period of time with improved bioavailability. However, poorly soluble drugs pose problems for achieving this goal. The selection of formulation is considered to play an essential role in the development of a successful product of a poorly soluble molecule. Numerous approaches are being followed by the research scientists all over the world to improve the solubility of poorly water soluble molecules with different formulation techniques ${ }^{1,2,3}$ like complexation, surfactant co-solvent systems, liquisolid systems, lipid systems etc. Rapid mouth disintegrating drug delivery systems were first developed as substitutes to unit dosage forms like tablets, capsules and syrups or suspensions for paediatric and geriatric patients who are having difficulty in swallowing traditional oral solid dosage forms. In continuation, different range of oral disintegrating tablets were developed and commercialized, which disintegrate at around $60 \mathrm{sec}$ after administering in the mouth without water. ${ }^{4}$ Wide range of drugs like neuroleptics, cardiovascular drugs, analgesics, antihistamines, anti-asthmatics, anti-diarrheal and erectile dysfunctions can be considered as candidates for oral fast disintegrating dosage forms. ${ }^{5}$ The aim of present work is to know the effect of transcutol HP on increasing the solubility and thereby bioavailability of poorly water soluble drugs. For poorly water soluble drugs the rate limiting step for absorption is the disintegr tion followed by dissolution of the drug, hence the objective of majority of formulation scientists is to improve the disintegration of solid dosage
Submission Date: 14-09-2017; Revision Date: 08-11-2017; Accepted Date: 26-11-2017

DOI: 10.5530/ijper.52.3.46 Correspondence: Dr. Pondugula Sudhakara Reddy,

AGM, Hetero Labs Ltd, Hetero Corporate Office, 7-2-A2, Industrial Estate, Sanath Nagar, Hyderabad - 500018, Telangana, INDIA.

Phone: +91-9492031152 E-mail: sudhakarpharma@ gmail.com / pondugulasr@ gmail.com

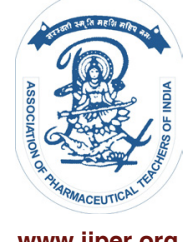

www.ijper.org 
forms followed by dissolution of solid dosage form with different approaches of solid dispersions like hot melt extrusion, compression moulding, fusion method and solvent evaporation methods. Oral fast dissolving films contains water soluble polymer which allows the films to quickly hydrate by saliva, adhere to mucosa and disintegrate in seconds followed by releasing of active ingredient for oro-mucosal absorption when administered on the tongue. ${ }^{6}$ These films or strips can reportedly incorporate soluble, insoluble or taste masked drug substances. Films are manufactured in large sheet and then divided into individual dosage units by cutting for suitable packaging in a range of pharmaceutically acceptable formats. Orally fast dissolving films (OFDFs) are useful in patients such as bedridden, geriatric, paediatric, developmentally disabled, feeling difficulty in swallowing conventional dosage forms. ${ }^{7}$ OFDFs can give quick absorption and immediate bioavailability of drugs due to high blood flow as permeability of oral mucosa is 4 to 1000 times greater than that of skin absorption. $^{8}$

There are four methods for manufacturing of OFDFs available, those are solvent casting, hot melt extrusion, semisolid casting, solid dispersions. However the most common method used in industry are solvent-casting and hot-melt extrusion methods.

\section{Solvent casting method ${ }^{9}$}

OFDFs are preferably formulated using the solvent casting method. In this process initially all the water soluble (plasticizers, sweeteners etc.) ingredients including active ingredients are dissolved in solvent to form a clear solution. Then the remaining ingredients are dissolved in smaller amounts in the above aqueous clear solution and filtered. The entrapped air is removed by vacuum and casted as film on appropriate plates or conveyers which are non-stick and allowed to dry. The films are then dried and cut in to pieces with desired size $\left(1 \mathrm{~cm}^{2}\right)$. Advantages of this method are uniformity in thickness, glossy appearance of film, more flexible and good physical properties. The disadvantages with this process are polymers must be soluble in volatile solvent or purified water to form stable solution with a reasonable minimum solvent.

\section{Hot melt extrusion ${ }^{10}$}

Hot melt extrusion is a technique where drug, polymer and excipients are mixed together and extruded under high temperature to form a homogenous liquid mass which is cast on the drying tunnel and finally slitting of mass to form smooth film. The films are punched, pouched and sealed. The major advantages of this technique are solvent free process, few unit operations involved, not required compressibility properties for API selection, uniformity in dosage forms.

\section{Semisolid casting ${ }^{11}$}

In this method, water soluble film forming polymers are mixed with the solution of acid insoluble polymer to get homogenous viscous solution (e.g. cellulose acetate phthalate, cellulose acetate butyrate). Plasticizers are added to form gelled mass and smooth cast on nontreated casting film. The ratio between acid insoluble polymer and film forming polymer should be 1:4.

\section{Solid dispersion extrusion ${ }^{12}$}

Solid dispersions by extrusion method are prepared by mixing of immiscible components, drug and then this mixture is shaped in to strips by pouring method in dies.

\section{MATERIALS AND METHODS}

Ezetimibe, a gift sample from Lupin Ltd., Pune, Transcutol HP, a gift sample from Gattefosse India Pvt. Ltd., Goa., HPMC E5, HPMC E6, HPMC E15 are gift samples from Colorcon India Pvt. Ltd., and other ingredients like pectin, sodium saccharin, orange oil, PEG-400 from India glycols limits, citric acid from R.M. chemicals are utilized from laboratory.

\section{Preparation of oral fast dissolving films (OFDFs)}

The OFDFs were prepared by using solvent casting method in petri plate. In the present investigation it was proposed to prepare film containing $10 \mathrm{mg}$ of drug ezetimibe in $1 \mathrm{~cm}^{2}(1 \times 1 \mathrm{~cm})$ film. The amount of drug to be incorporated into the film was calculated based on this assumption and the calculations.

\section{Procedure for preparation of ezetimibe OFDFs}

Formulae of ezetimibe OFDFs are presented in the Table 1. Solvent casting method was used for preparation of films using polymers (HPMC E5, E6, E15 and pectin). Initially the polymer was weighed accurately and dissolved in half quantity of water and mixed on magnetic stirrer. Ezetimibe was weighed and dissolved in transcutol HP. Citric acid and sodium saccharine were both dissolved in remaining amount of water. This solution was added to the polymeric solution and stirred well using a magnetic stirrer to obtain a homogenous solution, followed by the addition of PEG-400 as plasticizer and flavouring orange oil. This solution was allowed to stand for $30 \mathrm{~min}$ for deaeration of the solution. Solution was then casted in to petri dish and kept in hot air oven for $8-10 \mathrm{~h}$ at $50^{\circ} \mathrm{C}$. After drying, films were removed. Thus the obtained large film was cut into 


\begin{tabular}{|c|c|c|c|c|c|c|c|c|c|c|c|}
\hline జิ & $\mid \begin{array}{l}L \\
\mathbb{ల} \\
0\end{array}$ & & & & ণ্ণি & $\Sigma$ & 8 & 으 & - & $\begin{array}{l}\text { N̦ } \\
\text { on }\end{array}$ & 우 \\
\hline$\frac{O}{\dot{w}}$ & $\left|\begin{array}{l}0 \\
0 \\
ల\end{array}\right|$ & & & & $\stackrel{q}{q}$ & $\Sigma$ & 8 & 으 & - & 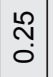 & 우 \\
\hline$\stackrel{\infty}{\dot{w}}$ & $\left|\begin{array}{l}0 \\
\stackrel{\rho}{\infty}\end{array}\right|$ & & & & 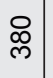 & $\bar{\Sigma}$ & ৪ & 우 & - & 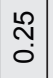 & 우 \\
\hline$\grave{\text { Lे }}$ &  & , & & ' & 怘 & $\Sigma$ & 8 & 우 & - & 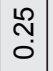 & 우 \\
\hline$\stackrel{\varrho}{\dot{u}}$ & 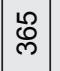 & ' & & ' & প্ল & $\Sigma$ & 8 & 으 & - & 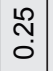 & 우 \\
\hline$\stackrel{\llcorner}{\dot{w}}$ & $\mid \begin{array}{l}0 \\
0 \\
ల\end{array}$ & 1 & & ণ্ণি & ' & $\Sigma$ & 8 & 으 & - & 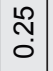 & 으 \\
\hline 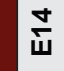 & $\mid \begin{array}{l}0 \\
0 \\
ల\end{array}$ & 1 & & $\stackrel{\text { L }}{\circ}$ & ' & $\Sigma$ & 8 & 으 & - & 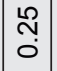 & 으 \\
\hline$\stackrel{m}{w}$ & $\mid \begin{array}{l}\mathscr{\ell} \\
\mathbb{m}\end{array}$ & ' & & 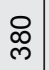 & ' & $\bar{\Lambda}$ & 8 & 우 & - & 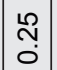 & 우 \\
\hline$\stackrel{N}{\mathrm{U}}$ & $\left|\begin{array}{l}0 \\
0 \\
ల\end{array}\right|$ & ' & & 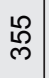 & ' & $\bar{\wedge}$ & 8 & 우 & - & 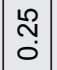 & 으 \\
\hline$\overline{\dot{w}}$ & $\mid \begin{array}{l}0 \\
\varnothing \\
ల\end{array}$ & 1 & & প్లి & 1 & $\bar{\Lambda}$ & 8 & 우 & - & \begin{tabular}{l}
$\stackrel{L}{2}$ \\
\hdashline
\end{tabular} & 으 \\
\hline$\stackrel{ }{\dot{u}}$ & $\mid \begin{array}{l}0 \\
\mathbb{ల}\end{array}$ &. & 官 & ' & ' & $\bar{\Lambda}$ & 8 & 우 & - & $\begin{array}{c}\stackrel{L}{ } \\
0 \\
0\end{array}$ & 으 \\
\hline 요 & $\mid \begin{array}{l}\mathscr{D} \\
\mathbb{m}\end{array}$ & 1 & 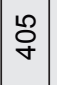 & ' & ' & $\bar{\Lambda}$ & 8 & 으 & - & \begin{tabular}{l}
$\stackrel{L}{2}$ \\
\hdashline \\
0
\end{tabular} & 우 \\
\hline జึ & $\mid$\begin{tabular}{l}
$\mathscr{\ell}$ \\
\hdashline
\end{tabular} & ' & $\left|\begin{array}{l}\infty \\
\infty \\
m\end{array}\right|$ & ' & ' & $\bar{\Lambda}$ & 8 & 우 & - & $\left|\begin{array}{c}\stackrel{2}{2} \\
0\end{array}\right|$ & 으 \\
\hline w & $\begin{array}{l}\stackrel{L}{0} \\
\text { r }\end{array}$ & . & 总 & ' & ' & $\bar{\Lambda}$ & 8 & 으 & - & 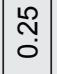 & 으 \\
\hline ய̊ & $\left|\begin{array}{l}0 \\
0 \\
0\end{array}\right|$ & . & 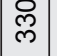 & . & ' & $\Sigma$ & 8 & & - & 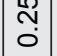 & $\stackrel{\circ}{-}$ \\
\hline 占 & $\mid \begin{array}{l}\mathscr{L} \\
\mathbb{ల}\end{array}$ & ণ্ণ্ণ & , & , & ' & $\bar{\lambda}$ & 8 & 우 & - & 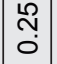 & 우 \\
\hline 岀 & $\mid \begin{array}{l}\text { 㤂 } \\
\text { | }\end{array}$ & 导 & ' & ' & . & $\bar{\Lambda}$ & 8 & 으 & - & $\mid \begin{array}{c}\stackrel{2}{ } \\
\vdots \\
0\end{array}$ & 으 \\
\hline జึ & \begin{tabular}{|l|} 
\\
0 \\
ల.
\end{tabular} & $\begin{array}{l}\stackrel{\infty}{0} \\
\text { | }\end{array}$ & ' & . & ' & $\Sigma$ & 8 & 으 & - & 岕 & 우 \\
\hline జี & $\mid \begin{array}{l}0 \\
0 \\
\text { 怘 }\end{array}$ & 怘 & ' & ' & I & $\bar{\Lambda}$ & 8 & 으 & - & $\mid \begin{array}{c}\stackrel{2}{ } \\
\vdots \\
0\end{array}$ & 으 \\
\hline $\bar{u}$ & \begin{tabular}{|l|} 
\\
0 \\
ల.
\end{tabular} & ల్లి & & ' & ' & $\Sigma$ & 8 & 우 & - & $\mid \begin{array}{c}\stackrel{2}{2} \\
0\end{array}$ & 우 \\
\hline 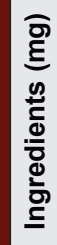 & 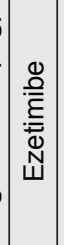 & $\begin{array}{l}\text { 邑 } \\
0 \\
\sum_{0} \\
\text { ํㅗ }\end{array}$ &  & 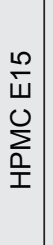 & 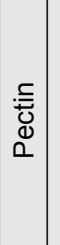 & 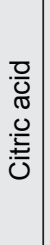 & 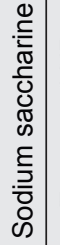 & 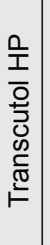 & 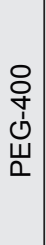 & $\mid \begin{array}{l}\overline{\overline{0}} \\
\bar{\Phi} \\
\bar{\Phi} \\
\overline{\widetilde{w}} \\
\bar{\sigma} \\
\end{array}$ & 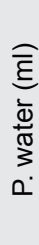 \\
\hline
\end{tabular}

pieces with the area of $1.0 \mathrm{~cm}^{2}(1 \mathrm{~cm}$ length $\mathrm{x} 1 \mathrm{~cm}$ breadth).

\section{Evaluation of OFDFs}

The oral fast dissolving films were evaluated for their dissolution, organoleptic characteristics and mechanical properties like thickness, dryness, tensile strength and folding endurance, transparency, disintegration time, surface $\mathrm{pH}$, moisture loss, moisture uptake and uniformity of drug content were also evaluated.

\section{Organoleptic properties}

The organoleptic characters like colour, odour and appearance were examined physically and reported accordingly.

\section{Thickness}

Precise film thickness measurements were carried out using calibrated digital micrometre NIKON Digi-Micro screw gauge and then mean average $(n=3)$ is calculated subsequently. Uniformity of film weight is calculated in triplicate by cutting the film in $1 \times 1 \mathrm{~cm}$ for determining the weight of film. Thickness of the film measured at five points i.e. from the centre to all the four corners and mean thickness is calculated. It is necessary to determine the uniformity in thickness as it is directly related to accuracy of dose in the film.

\section{Dryness}

The ability to adhere a piece of paper pressed between two strips was studied in dryness test. ${ }^{13}$ There were eight stages involved in film drying process as per the literature, which were viz. dry-to touch, dry-to-recoat, dry hard, set-to-touch, dust-free, dry-through, tack-free and dry print-free were observed. These tests are used to evaluate dryness of films in pharmaceutical industry especially for orally disintegrating films. ${ }^{6}$ Tack-free is the tenacity with which, the strip adheres to a piece of paper that has been pressed into contact with the other strip, instruments are also available for conducting this study.

\section{Tensile strength}

Mechanical properties of the film formers are important for film casting on release liners, punching and packaging. Tensile strength is defined as maximum stress applied at which, the film breaks. A quality control test was adapted using number 5 test specimen. Tensile strength test was performed using stable micro system's film support rig apparatus to assess strength and elasticity of the prepared films. $1 \mathrm{~cm}^{2}$ film was taken and 
kept between two cup holder and tight them with screws and place it on the film support rig instrument. It can be calculated from applied load at rupture divided by the strip cross-sectional area given in the equation below:

Tensile strength $=\frac{\text { load at failure }}{\text { strip thickness }} \times 100$

\section{Folding endurance \& Transparency}

Folding endurance to determine mechanical properties of film and was measured by repeatedly folding of the film at the same place to the extent where film breaks. The number of times the film is folded without breaking is calculated as the folding endurance value. ${ }^{14}$ This parameter was checked simply by visual inspection of films.

\section{Disintegration time}

A film was placed onto $2 \mathrm{ml}$ distilled water taken in petri dish. Time taken by the film to dissolve completely is considered as the disintegrating time. The disintegration time is the time when the film starts to break or disintegrates completely, normally disintegration time for oral films s within 2 min. ${ }^{15}$

\section{Dispersion time}

For determination of in vitro dispersion time, one film with the dimensions $1 \times 1 \mathrm{~cm}$ was placed in a beaker containing $10 \mathrm{ml}$ of $\mathrm{pH} 6.8$ phosphate buffer at $37 \pm 0.5^{\circ} \mathrm{C}$ and the time required for complete dispersion was determined. ${ }^{16}$

\section{Surface pH}

The surface $\mathrm{pH}$ of OFDF was determined to investigate the possibility of any side effects in in vivo studies. As an acidic or alkaline $\mathrm{pH}$ may cause irritation to the oral mucosa, it was ensured to keep the surface $\mathrm{pH}$ as close to $\mathrm{pH} 6.8$ (oral cavity $\mathrm{pH}$ ). The $\mathrm{pH}$ of an oral film was usually determined by putting the film in petri dish and film was made wet with distilled water and noting $\mathrm{pH}$ by touching the film surface with a $\mathrm{pH}$ paper. ${ }^{15}$

\section{Moisture loss, moisture uptake}

Moisture loss was determined by weight variation. Initial weight of the film was determined and afterward film was kept in a desiccator containing calcium carbonate for about $72 \mathrm{~h}$. Films were then taken out and weighed. Percentage moisture loss is calculated by using the following formula as below. ${ }^{16}$
$\%$ Moisture loss $=\frac{\text { initial weight }- \text { final weight }}{\text { initial weight }} \times 100$

Moisture uptake of an oral thin film was determined by expose to the environment with a relative humidity $75 \%$ at room temperature for $72 \mathrm{~h}$. Percentage moisture uptake is calculated as $\%$ weight gain of the films as per below formula. ${ }^{17}$

$\%$ Moisture loss $=\frac{\text { final weight }- \text { initial weight }}{\text { initial weight }} \times 100$

\section{Uniformity of drug content}

Drug Content of oral fast dissolving films were determined by standard assay method taken for 10 individual samples as per the test procedures. The acceptance value of the test is less than 15 in accordance with all pharmacopoeia. A film of size $1 \mathrm{~cm}^{2}$ was cut and kept in $100 \mathrm{ml}$ of volumetric flask containing solvent. This was then shaken in a mechanical shaker till it was dissolved to get a homogeneous solution and then filtered. The drug was determined spectroscopically after appropriate dilution and dilutions were measured at $232 \mathrm{~nm}$ to get absorbance. $^{18}$

\section{DISSOLUTION}

The dissolution studies were carried out using USP dissolution apparatus type V (Paddle over disc, Electro lab, Mumbai, India) at $37 \pm 0.5^{\circ} \mathrm{C}$ and $50 \mathrm{rpm}, 900 \mathrm{ml}$ of $\mathrm{pH} 6.8$ phosphate buffer solution served as medium for ezetimibe OFDFs and $5 \mathrm{ml}$ of samples were withdrawn at the time intervals of $5 \mathrm{~min}$ and $10 \mathrm{~min}$. Each film having $10 \mathrm{mg}$ of ezetimibe was placed in dissolution apparatus.

\section{Compatibility studies}

Drug-polymer compatibility studies were performed by Fourier transform infrared spectroscopy (FTIR) using pressed pellet technique. The pellet was prepared by compression of small pinch of the material with potassium bromide (KBR) and analysed at wave number range $4000-500 \mathrm{~cm}^{-1}$.

\section{Powder X-ray diffractometry}

The powder X-ray diffractograms of pure drugs ezetimibe, physical mixtures of optimized formulations, placebo films and optimized film formulations of ezetimibe were recorded on pXRD with copper radiation in the $2 \theta$ range of $5-80^{\circ}$ at $40 \mathrm{~mA}$ and $45 \mathrm{KV}$ to identify the possible interactions. 


\section{Differential scanning calorimetry (DSC)}

Thermal analysis studies were performed to pure APIs ezetimibe and optimized film formulations of ezetimibe. The samples were sealed in aluminium pan and heated at $10^{\circ} \mathrm{C} / \mathrm{min}$ rate from $20-200^{\circ} \mathrm{C}$ with empty aluminium pan kept as reference sample.

\section{Surface texture}

Surface texture of ezetimibe was studied by SEM analysis. The surface morphology of pure APIs ezetimibe and optimized films of ezetimibe were observed by scanning electron microscopy.

\section{RESULTS AND DISCUSSION}

\section{Drug release of OFDFs}

Ezetimibe OFDFs drug release was around $90 \%$ for all the formulations within $10 \mathrm{~min}$. The drug release data shown in Table 2 and release profiles in Figure 1. The drug release in the formulations coded E1 - E20 was ranging from $86.4 \%$ to $99.4 \%$ within $10 \mathrm{~min}$. Thus from the dissolution studies of all the films developed with different grades of HPMC E series and pectin clearly showed that the drug release was high due to enhanced solubility of the ezetimibe, which indicated that the solubility of ezetimibe was increased in oral fast disintegrating films.

\section{Evaluation of oral fast dissolving films}

Oral fast dissolving films were evaluated for their organoleptic characteristics and mechanical properties like thickness, dryness, tensile strength, folding endurance, transparency, surface texture, disintegration time, drug content, and surface $\mathrm{pH}$.

\section{Organoleptic characteristics}

The organoleptic characteristics such as description, appearance, and odour were observed for films of ezetimibe. They were found to be clear and free from foreign materials and air bubbles without odour.

\section{Thickness}

The thickness of the ezetimibe OFDFs formulations E1 - E20, developed with HPMC E5, E6 and E15 and pectin were found ranging from $0.116 \mathrm{~mm}$ to $0.358 \mathrm{~mm}$. From the obtained thickness data it was observed that the thickness of the film was increased by increasing in the concentration of the film former. Hence, the thickness of the film was directly proportional to its film former concentration.

\begin{tabular}{|c|c|c|c|c|c|c|c|}
\hline Formulation & $\begin{array}{l}\text { Thickness } \\
(\mathbf{m m})\end{array}$ & $\begin{array}{c}\text { Folding } \\
\text { endurance }\end{array}$ & Transparency & $\begin{array}{l}\text { Surface } \\
\text { texture }\end{array}$ & $\begin{array}{c}\text { Disintegration } \\
\text { time }\end{array}$ & $\begin{array}{c}\text { Surface } \\
\text { pH }\end{array}$ & $\begin{array}{c}\text { Drug content } \\
(\%)\end{array}$ \\
\hline E1 & 0.131 & 50 & Transparent & Smooth & $24 \mathrm{sec}$ & 6.85 & 101.9 \\
\hline E2 & 0.141 & 75 & Transparent & Smooth & $30 \mathrm{sec}$ & 6.80 & 98.0 \\
\hline E3 & 0.181 & 89 & Transparent & Smooth & $35 \mathrm{sec}$ & 6.75 & 99.0 \\
\hline E4 & 0.241 & 96 & Transparent & Smooth & $49 \mathrm{sec}$ & 6.80 & 101.0 \\
\hline E5 & 0.278 & 105 & Transparent & Smooth & $1 \mathrm{~min} 5 \mathrm{sec}$ & 6.85 & 98.2 \\
\hline E6 & 0.116 & 184 & Transparent & Smooth & $36 \mathrm{sec}$ & 6.80 & 100.0 \\
\hline E7 & 0.174 & 189 & Transparent & Smooth & $48 \mathrm{sec}$ & 6.80 & 101.3 \\
\hline E8 & 0.215 & 193 & Transparent & Smooth & $59 \mathrm{sec}$ & 6.85 & 99.7 \\
\hline E9 & 0.310 & 196 & Transparent & Smooth & $1 \mathrm{~min} 2 \mathrm{sec}$ & 6.75 & 98.0 \\
\hline E10 & 0.358 & 199 & Transparent & Smooth & $1 \mathrm{~min} 30 \mathrm{sec}$ & 6.75 & 99.0 \\
\hline E11 & 0.119 & 263 & Transparent & Smooth & $40 \mathrm{sec}$ & 6.80 & 99.0 \\
\hline E12 & 0.123 & 274 & Transparent & Smooth & $49 \mathrm{sec}$ & 6.80 & 100.6 \\
\hline E13 & 0.125 & 291 & Transparent & Smooth & $54 \mathrm{sec}$ & 6.80 & 98.0 \\
\hline E14 & 0.214 & 297 & Transparent & Smooth & $1 \mathrm{~min} 20 \mathrm{sec}$ & 6.75 & 97.3 \\
\hline E15 & 0.258 & 300 & Transparent & Smooth & $1 \mathrm{~min} 50 \mathrm{sec}$ & 6.80 & 99.0 \\
\hline E16 & 0.124 & 188 & Transparent & Smooth & $26 \mathrm{sec}$ & 6.80 & 99.6 \\
\hline E17 & 0.167 & 192 & Transparent & Smooth & $32 \mathrm{sec}$ & 6.75 & 99.7 \\
\hline E18 & 0.191 & 200 & Transparent & Smooth & $41 \mathrm{sec}$ & 6.75 & 98.67 \\
\hline E19 & 0.212 & 227 & Transparent & Smooth & $50 \mathrm{sec}$ & 6.75 & 100.42 \\
\hline E20 & 0.265 & 250 & Transparent & Smooth & $1 \mathrm{~min}$ & 6.80 & 99.57 \\
\hline
\end{tabular}



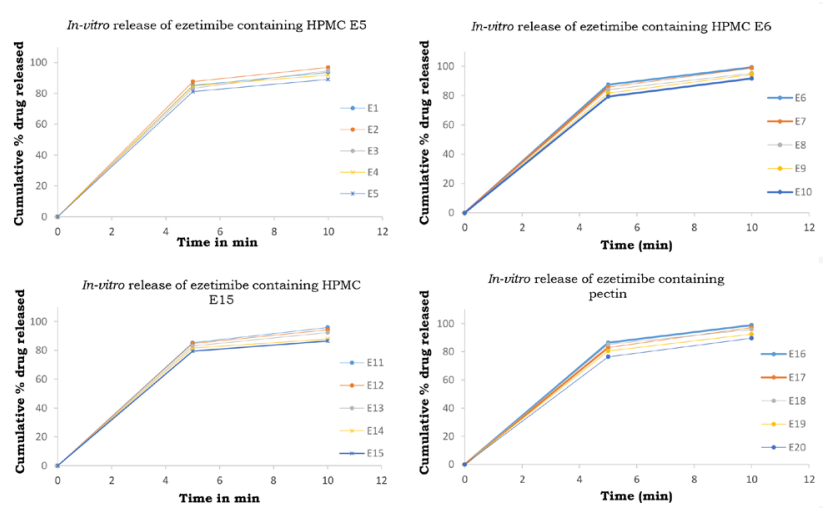

Figure 1: Dissolution profiles of ezetimibe OFDFs.

\section{Dryness}

The dryness of ezetimibe OFDFs formulations E1 E20 was shown by their non-sticky nature to the papers on either side of the film.

\section{Folding endurance}

Formulations E1-E5 folding endurance was in the range of 50-105, E6-E10 was in the range of 184-199, E11E15 was in the range of 263-300 and E16-E20 was in the range of 188-250. The observed folding endurance data of the films developed with various viscosities and concentrations of film formers indicated that the increase in viscosities and concentrations of the film lead to increase in the folding endurance of the films.

\section{Transparency}

The transparency of ezetimibe OFDFs was observed by placing the films before black background and found that all the films were transparent.

\section{Disintegrating time}

The formulations E1 - E5 developed with different concentrations of HPMC E5, disintegration time were found in the range of $24 \mathrm{sec}$ to $1 \mathrm{~min} 5 \mathrm{sec}$, formulation E6 to E10 developed with varied concentration of HPMC E6 were in the range from $30 \mathrm{sec}$ to $1 \mathrm{~min} 30 \mathrm{sec}$. Formulations E11 - E15 taken with HPMC E15 having altered concentrations were in the range of $40 \mathrm{sec}$ to $1 \mathrm{~min} 50 \mathrm{sec}$. The formulations E16 - E20 prepared with pectin having different concentrations were ranging from $26 \mathrm{sec}$ to $1 \mathrm{~min}$. The data of disintegration time indicates that increasing the concentrations of polymer along with different viscosities tends to increase the disintegration time. The films disintegration pattern shown as below in Figure 2 for ezetimibe OFDFs at initial, around $15-20 \mathrm{sec}$ and final completion time snaps were represented.

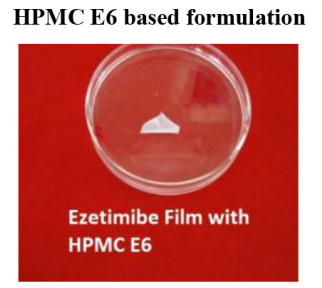

Before disintegration
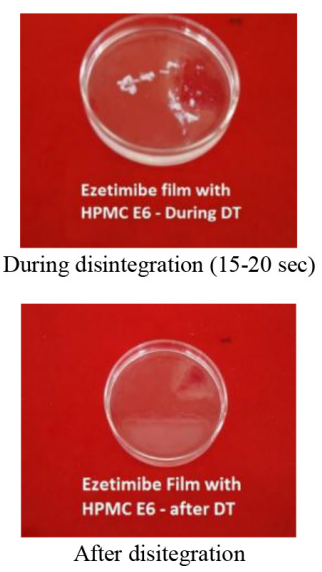

Pectin based formulation

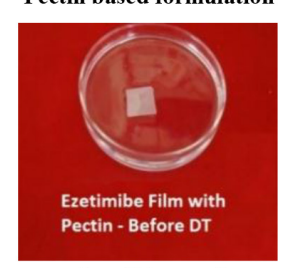

Before disintegration

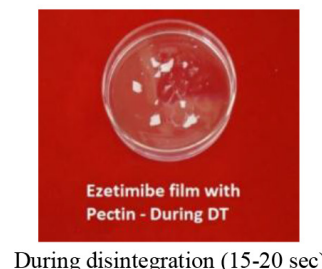

During disintegration $(15-20 \mathrm{sec})$

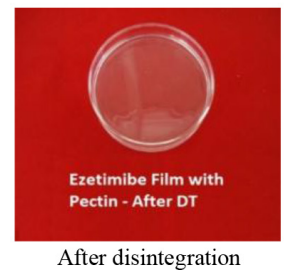

Figure 2: Ezetimibe OFDFs disintegrating pattern of E6 and E16 formulations.

\section{Surface pH}

The surface $\mathrm{pH}$ of the film should be similar to that of saliva i.e. 6.8 as it is being kept in the oral cavity for dissolution for avoiding the irritation. The $\mathrm{pH}$ of ezetimibe was measured in triplicate for each sample and found in the range from $6.75-6.85$ with an average of around $\mathrm{pH} 6.80$ which, indicated that $\mathrm{pH}$ range was well within the targeted $\mathrm{pH}$ and suitable in oral cavity.

\section{Moisture loss and moisture uptake}

The formulated OFDFs were evaluated and the \%moisture loss was calculated. A reduced $\%$ moisture loss was observed with increase in polymer concentration varying from $6.5 \%$ to $4.50 \% \mathrm{w} / \mathrm{w}$ for ezetimibe films. The moisture uptake studies indicated an increase in uptake of moisture with increase in concentration of polymer and found to be in the range of $6.5 \%$ to $9.5 \% \mathrm{w} / \mathrm{w}$ which, may be due to increased hydrophilic nature of polymer with increase in viscosity of the polymer.

\section{Drug Content}

The Content uniformity was worked out on individual films of 10 samples. A film of size $1 \mathrm{~cm}^{2}$ was cut and kept in $100 \mathrm{ml}$ of volumetric flask containing solvent. This was then shaken in a mechanical shaker till it was dissolved to get a homogeneous solution and then filtered. The drug was determined spectroscopically after appropriate dilution and measured at $232 \mathrm{~nm}$. For E1 - E20 


\begin{tabular}{|c|c|c|c|}
\hline \multirow{2}{*}{$\begin{array}{l}\text { Formulation } \\
\text { code }\end{array}$} & & \multicolumn{2}{|c|}{ Time (min) } \\
\hline & & 5 & 10 \\
\hline E1 & \multirow{20}{*}{ 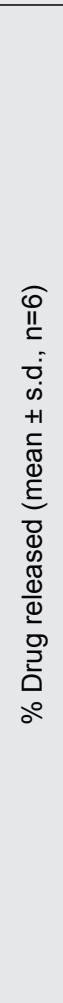 } & $85.20 \pm 0.88$ & $93.60 \pm 0.67$ \\
\hline E2 & & $87.63 \pm 0.58$ & $96.87 \pm 0.79$ \\
\hline E3 & & $83.26 \pm 0.88$ & $94.70 \pm 0.47$ \\
\hline E4 & & $84.87 \pm 0.87$ & $91.89 \pm 0.46$ \\
\hline E5 & & $81.20 \pm 0.16$ & $89.16 \pm 0.97$ \\
\hline E6 & & $87.46 \pm 0.33$ & $99.40 \pm 0.49$ \\
\hline E7 & & $85.80 \pm 0.89$ & $98.80 \pm 0.67$ \\
\hline E8 & & $84.10 \pm 0.15$ & $95.20 \pm 0.67$ \\
\hline E9 & & $81.70 \pm 0.48$ & $94.40 \pm 0.97$ \\
\hline E10 & & $79.40 \pm 0.57$ & $91.70 \pm 0.59$ \\
\hline E11 & & $85.20 \pm 0.39$ & $95.80 \pm 0.24$ \\
\hline E12 & & $84.70 \pm 0.28$ & $94.26 \pm 0.19$ \\
\hline E13 & & $82.92 \pm 0.64$ & $92.30 \pm 0.99$ \\
\hline E14 & & $81.50 \pm 0.64$ & $87.80 \pm 0.28$ \\
\hline E15 & & $79.40 \pm 0.97$ & $86.45 \pm 0.89$ \\
\hline E16 & & $86.40 \pm 0.39$ & $98.80 \pm 0.46$ \\
\hline E17 & & $82.90 \pm 0.64$ & $97.16 \pm 0.33$ \\
\hline E18 & & $85.20 \pm 0.33$ & $95.80 \pm 0.26$ \\
\hline E19 & & $80.50 \pm 0.26$ & $92.46 \pm 0.13$ \\
\hline E20 & & $76.40 \pm 0.34$ & $89.59 \pm 0.22$ \\
\hline
\end{tabular}

formulations developed with HPMC E5, E6, E15 and pectin with different concentrations the drug content was found in the range of 97.3-101.9\%. Even though all the formulations drug content within the specification range, $100 \%$ and $99.6 \%$ of ezetimibe in each formulation developed with HPMC E6 and pectin polymers respectively. The ezetimibe OFDF's evaluation parameters were shown in Table 3.

\section{Compatibility study by FTIR}

The FTIR spectrum of the ezetimibe and ezetimibe optimized formulation E6 analysed and the broad peak at the band range of $3285.95-3408.33 \mathrm{~cm}^{-1}$ represents the $\mathrm{OH}$ group, a sharp peak obtained at $2914.54 \mathrm{~cm}^{-1}$ represents $\mathrm{CH}=\mathrm{CH}$ group, $\mathrm{C}=\mathrm{O}$ (lactum ring) group was present in the drug ezetimibe and confirmed by the peak obtained at the band width $1722.49 \mathrm{~cm}^{-1}$, a sharp peak obtained at $1491.02 \mathrm{~cm}^{-1}$ due to $\mathrm{CN}$ bending, and a peak obtained at $1222.91 \mathrm{~cm}^{-1}$ was due to $\mathrm{C}$-F bending. The same characteristic bands were observed in the ezetimibe optimized formulation E6 indicating that there was no physical incompatibility in between the ingredients used to develop films.

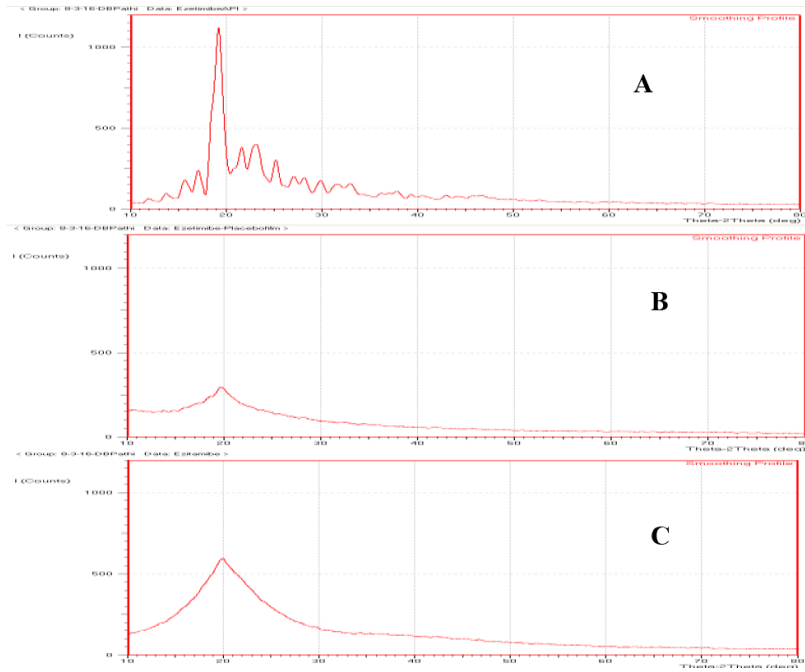

Figure 3: X-ray diffractograms of A) ezetimibe B) placebo film C) ezetimibe OFDF formulation E6.

\section{Powder X-ray diffractometry}

Powder X-ray diffractograms of ezetimibe, physical mixture, placebo film and ezetimibe optimized formulation E6 are shown in Figure 3. The powder X-ray diffractograms of ezetimibe showed distinct sharp peaks obtained at diffraction angles from $13.74^{\circ}$ to $37.8^{\circ}$ indicating the crystalline state of the ezetimibe. The intensity of peaks was reduced within the range of diffraction angle of $13.47^{\circ}$ to $27.06^{\circ}$ in the optimized ezetimibe film. However, the peak intensity was completely reduced in ezetimibe formulation $\mathrm{E} 6$ indicating that the nature of the drug ezetimibe was converted to amorphous form after formulating as film by using transcutol HP. The pXRD data of physical mixture and placebo film does not shown any sharp peaks.

\section{Differential scanning calorimetry (DSC)}

Figure 4 showed the DSC thermograms of both ezetimibe pure API and ezetimibe optimized film formulation E6. The sharp peak obtained at the range of $160-170^{\circ} \mathrm{C}$ represents the melting point of pure ezetimibe and it matches the literature values. The sharpness of the peak represents the crystalline nature of the pure ezetimibe. Where in, the ezetimibe optimized film formulation E6 DSC thermogram does not contains sharp peak and a broad peak obtained and it represents the ezetimibe was converted into amorphous form and it results in the enhancement of the drug release rate, it was due to the effect of transcutol HP.

\section{Surface texture}

Surface texture of films were found to be smooth in nature irrespective of the films developed. Figure 5 and 

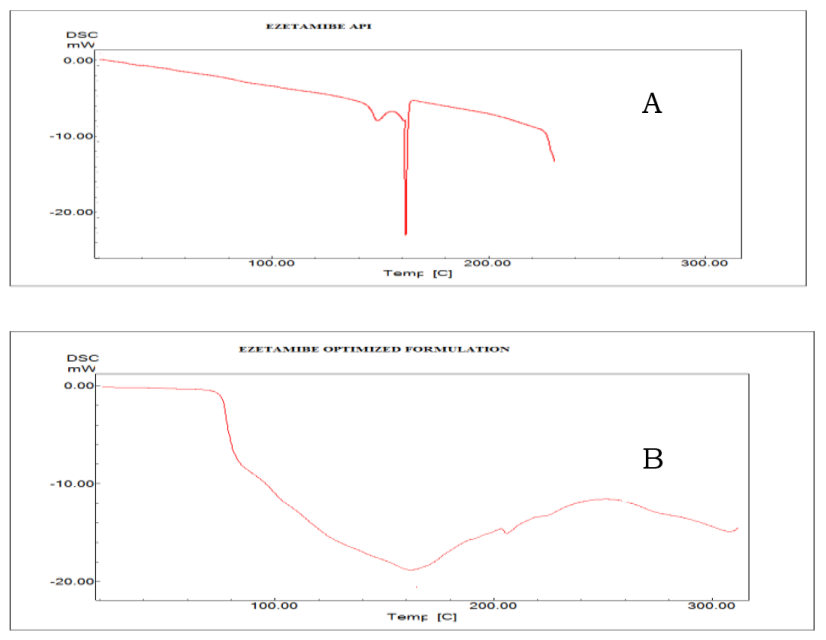

Figure 4: DSC thermograms of A) ezetimibe B) ezetimibe OFDF formulation E6.
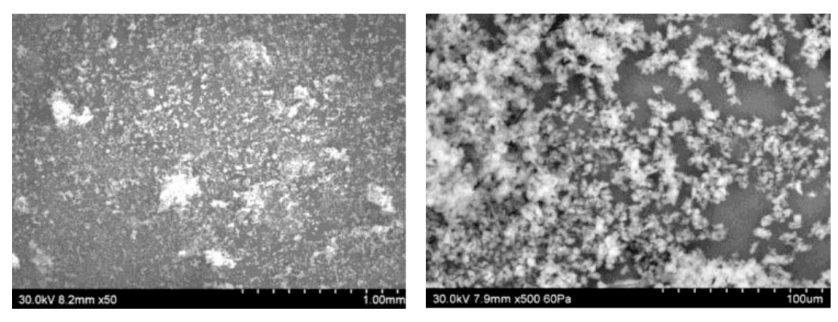

Figure 5: SEM images of ezetimibe pure API at different scales.
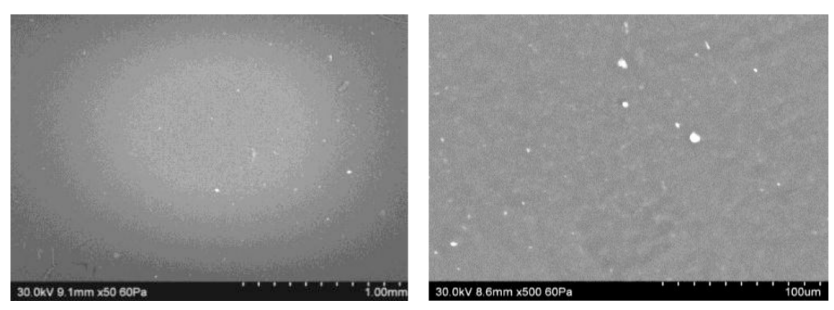

Figure 6: SEM images of ezetimibe OFDF formulation E6 at different scales.

6 showed the Scanning electron microscopy images of both ezetimibe pure API and ezetimibe film optimized formulation E6 at different scales. The crystals obtained at Figure 5 represents the pure ezetimibe API. Where in the ezetimibe OFDF formulation E6 Scanning electron microscopy images contained smooth surface represents the ezetimibe was in amorphous form and it results in the enhancement of the drug release rate, it was due to the effect of transcutol HP shown in Figure 6.

\section{Preparation of OFDFs without transcutol HP for the selected drugs}

From the above results it was concluded that the oral fast dissolving films of E6 of ezetimibe gave good results with respect to qualitative and drug release char-
Table 4: Comparative dissolution studies of ezetimibe optimized films and without transcutol HP films in pH 6.8.

\begin{tabular}{|c|c|c|}
\hline \multirow{2}{*}{$\begin{array}{c}\text { Time } \\
(\boldsymbol{m i n})\end{array}$} & \multicolumn{2}{|c|}{ \% Drug released (mean士s.d., $\mathbf{n = 6}$ ) } \\
\cline { 2 - 3 } & E6 & BE6 \\
\hline 5 & $87.5 \pm 0.33$ & $15.5 \pm 6.15$ \\
\hline 10 & $99.4 \pm 0.49$ & $22.2 \pm 7.27$ \\
\hline 15 & $99.6 \pm 0.14$ & $25.4 \pm 3.15$ \\
\hline 30 & $99.1 \pm 0.71$ & $30.2 \pm 2.44$ \\
\hline 45 & $98.6 \pm 0.18$ & $35.6 \pm 3.42$ \\
\hline 60 & $98.5 \pm 0.26$ & $40.5 \pm 1.28$ \\
\hline 90 & $98.7 \pm 0.57$ & $45.8 \pm 0.77$ \\
\hline
\end{tabular}

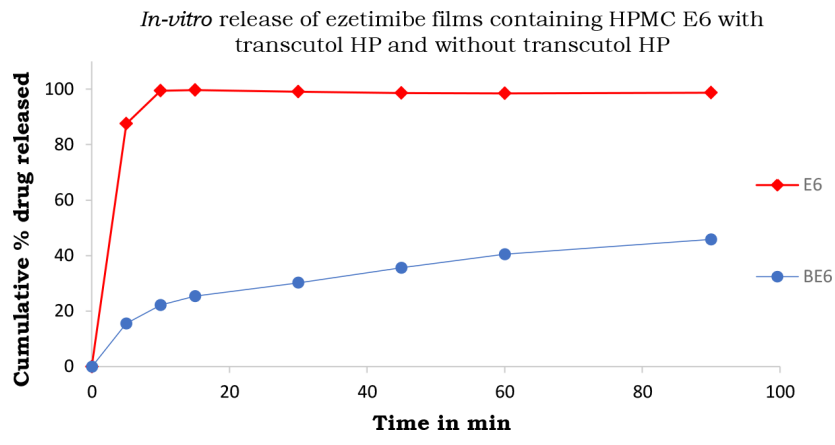

Figure 7: Comparative dissolution profiles of ezetimibe optimized films and without transcutol HP films.

acteristics. Hence, to assess the effect of transcutol HP in increasing the solubility of poorly soluble drug, films of ezetimibe was prepared with the same composition omitting transcutol HP under similar conditions and are coded as BE6. The prepared ezetimibe film without transcutol HP was evaluated for their folding endurance, drug content estimation, disintegration time and dissolution. The prepared films were able to give the satisfactory results with respect to drug content as $99.8 \%$ and folding endurance as 175 for BE6 formulation and the disintegration time was $90 \mathrm{sec}$ for BE6 formulation. The drug release studies were performed and the results are shown in Table 4 and Figure 7 in comparison with the films containing transcutol HP.

\section{CONCLUSION}

In the present study the solubility of selected drug ezetimibe was studied in different solubilizing agents and it was observed that, transcutol HP increased the solubility of the selected drug by 3 to 4 times. Based on the enhancement of solubility when compared with water solubility, it was proposed to prepare the oral fast dissolving film of ezetimibe using transcutol HP as solubilizing agent. The films were prepared by using 
HPMC E series with different viscosity grades and pectin using different drug-polymer concentrations. The prepared films were found to be good quality in nature with respect to the dissolution, thickness, disintegrating time, folding endurance, drug content etc. Based on the characteristics of the film formulations E6 for ezetimibe prepared with HPMC E6 gave good results with complete release of drug within 10 mins. Thus it can be concluded that transcutol HP can be used as solubilizing agent for poorly soluble drug like ezetimibe.

The study clearly indicated the influence of transcutol HP in enhancing the solubility of the poorly soluble drugs as the films made without transcutol HP failed to give the desired release characteristics within $10 \mathrm{~min}$.

\section{ACKNOWLEDGEMENT}

The authors are thankful to Vaageswari College of Pharmacy management and Dr. Reddys Laboratories Ltd for providing their facility to utilize research work and Lupin for Ezetimibe API sample and Gattefosse for their Transcutol HP as gift sample.

\section{CONFLICT OF INTEREST}

The authors declare no conflict of interest.

\section{ABBREVIATIONS}

HPMC: Hydroxypropyl Methyl Cellulose, OFDF: Oral Fast Dissolving Films; API: Active Pharmaceutical Ingredient; SEM: Scanning Electron Microscope; FTIR: Fourier Transmission Infrared; DSC: Differential Scanning Calorimetry.

\section{REFERENCES}

1. Colin W. Pouton., Formulation of poorly water soluble drugs for oral administration: physicochemical and physiological issues and the lipid formulation classification system., European Journal of Pharmaceutical Sciences., 2006;29(3-4):278-87.

2. Michael Hite, Stephen Turner,Cathy Federici, Part 1: oral delivery of poorly soluble drugs., Pharmaceutical Manufacturing and Packing Sourcer., Summer 03 issue. 2003.
3. Krishnaiah Y.S.R., Pharmaceutical technologies for enhancing oral bioavailability of poorly soluble drugs., Journal of Bioequvalence and Bioavailability. 2010;2(2):28-36.

4. Rajni Bala, Pravin Pawar, Sushil Khanna, Sandeep Arora, Orally dissolving strips: a new approach to oral drug delivery system., Int J Pharm Investig. 2013;3(2):67-76.

5. Dixit R.P., Puthli S.P., Oral strip technology: overview and future potential., J of Cont Release., 2009;139(2):94-107.

6. Mukem Bhattarai, Amit Kumar Gupta, Fast dissolving oral films: a novel trend to oral drug delivery system., Sunsari Technical College Journal. 2015;2(1):58-68.

7. Alpesh R. Patel, Dharmendra S. Prajapati, Jignyasha A. Raval., Fast dissolving films (FDFS) as a newer venture in fast dissolving dosage forms., International Journal of Drug Development and Research. 2010;2(2):232-46.

8. Hema Chaudhary, Samita Gauri, Permender Rathee, Vikash Kumar, Development and optimization of fast dissolving oro-dispersible films of granisetron $\mathrm{HCl}$ using Box-Behnken statistical design, Bulletin of Faculty of Pharmacy., Cairo University. 2013;51(2):193-201.

9. Dhagla R. Choudhary, Vishnu A. Patel, Usmangani K. Chhalotiya, Harsha V. Patel, Alisgar J. Kundawala, Development and characterization of pharmacokinetic parameters of fast-dissolving films containing levocetirizine, Sci Pharm. 2012;80(3):779-87.

10. Reeta Rani Thakur, Sonia Narwal, Orally disintegrating preparations: recent advancement in formulation and technology, J Drug Deliv Therap. 2012;2(3):87-96.

11. Panda BP, Dey NS, Rao MEB. Development of innovative orally fast disintegrating film dosage forms: a review, Int J Pharm Sci Nanotech. 2012;5(2):1666-74.

12. Renuka Mishra, Avani Amin, Manufacturing techniques of orally dissolving film., Pharmaceutical Technology., 2011;35(1):1-4.

13. Hema Chaudhary., Samita Gauri., Permender Rathee., Vikash Kumar., Development and optimization of fast dissolving oro-dispersible films of granisetron $\mathrm{HCl}$ using Box-Behnken statistical design, Bullet. Faculty Pharm., Cairo University. 2013;51:193-201.

14. Singh CK, Tiwari V, Shankar R, Mishra CP, Jain S, Jain S, et al. A short review on oral fast dissolving film containing cefpodoxime proxetil nanoparticle, World Journal of Pharmacy and Pharmaceutical Sciences. 2015;5(1):1549-77.

15. Yellanki SK, Jagtap S, Masareddy R, Disso film: A novel approach for delivery of phenobarbital; design and characterization, J. Young Pharm. 2011;3(3):181-8.

16. Bi $\mathrm{YX}$, Sunada H,Yonezawa $\mathrm{Y}$, Danjo K, Evaluation of rapidly disintegrating tablets by direct compression method. Drug Develop Ind Pharm. 1999;25(5):571-81.

17. Gorle AP, Gattani SG. Design and evaluation of polymeric ocular drug delivery system, Chem Pharm Bull (Tokyo). 2009;57(9):914-9.

18. Bala R, Pawar P, Khanna S, Arora S. Orally disintegrating strips: A new approach to oral drug delivery system, Int J Pharm Investi. 2013;3(2):67-76.

19. Maheswari KM, Devineni PK, Deekonda S, Shaik S, Uppala NP, Nalluri BN. Nalluri, Development and evaluation of mouth dissolving films of amlodipine besylate for enhanced therapeutic efficacy, Journal of pharmaceutics, article ID 520949. 2014;1-10.

20. Dinge A, Nagarsenker M. Formulation and evaluation of fast dissolving films for delivery of triclosan to the oral cavity, AAPS Pharm Sci Tech. 2008;9(2):349-56.

\section{SUMMARY}

- BCS class II drugs need the enhancement of the solubility thereby bioavailability, hence different techniques have been explored for the enhancement of the oral bioavailability. In the present study, it was studied the effect of transcutol HP and observed that, improved the solubility of ezetimibe by formulating the OFDFs having different concentrations of film formers indicated that all the prepared formulations were having the physical and chemical properties. Based on the results of all the formulations, optimized formulations have confirmed the improvement in the solubility and also blank formulations were prepared by using similar formula with omitting transcutol HP in the formulation. The results clearly indicated that, the influence of transcutol HP in optimized formulations shown complete drug release within $10 \mathrm{~min}$, whereas only $50 \%$ of drug release observed after $90 \mathrm{~min}$ in the formulation without transcutol HP. Hence the effect of transcutol HP was clearly established. 
PICTORIAL ABSTRACT

\begin{tabular}{|l|l|}
\hline Ezetimibe & $\begin{array}{l}\text { Preparation of ezetimibe } \\
\text { OFDFs by using solvent } \\
\text { casting method }\end{array}$ \\
\hline Film formers & Film casting \\
\hline Drying \\
Physical evaluation like: \\
\hline Organoleptic \\
\hline Thickness \\
\hline Weight variation \\
\hline Folding endurance \\
\hline Disintegration time \\
\hline Surface pH \\
\hline Chemical evaluation \\
\hline
\end{tabular}

About Authors

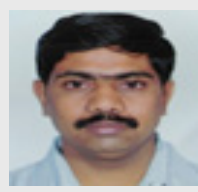

Dr. Pondugula Sudhakara Reddy: Asst. General Manager. Hetero Labs Ltd, Hetero Corporate Office, SanathNagar, Telangana, 500018, India.

Prof (Dr) K V Ramana Murthy: Professor of Pharmaceutics, AU College of Pharmaceutical Sciences, Andhra University, Vishakhapatnam, Andhra Pradesh, 530003, India.

Cite this article: Reddy PS, Murthy KVR. Formulation and Evaluation of Oral Fast Dissolving Films of Poorly Soluble Drug Ezetimibe Using Transcutol Hp. Indian J of Pharmaceutical Education and Research. 2018;52(3):398-407. 